\title{
The Behavior of Osteoblast-like Cells on Different Crystal Systems of Calcium Phosphate Ceramics in vitro
}

\author{
Hideyuki Ikumoto', Kenichi Matsuzaka ${ }^{2}$, Takashi Inoue ${ }^{2}$, Takeshi Uchiyama ${ }^{1}$ and Masao Yoshinari ${ }^{3}$ \\ '2nd Department of Oral and Maxillofacial Surgery, ${ }^{2}$ Department of Clinical Pathophysiology, Oral Health Science Center, and ${ }^{3}$ Depart- \\ ment of Dental Materials Science, Oral Health Science Center, Tokyo Dental College, 1-2-2 Masago, Mihama-ku, Chiba, 261-8502 Japan \\ (Received 21 August 2003; and accepted 5 September 2003)
}

\begin{abstract}
Calcium phosphate (Ca-P) ceramics are well known for their excellent osteo-conductivity. However, factors critical to the mineralization process of Ca-P ceramics are not fully understood, including the importance of the crystal system, the $\mathrm{Ca} / \mathrm{P}$ ratio, the solubility and the surface morphology of the materials. Therefore, this study was performed to evaluate the initial mineralization behavior of osteoblast-like cells on Ca-P ceramics of different crystal systems and $\mathrm{Ca} / \mathrm{P}$ ratios but with similar solubilities and surface morphologies. Cell attachment and cell proliferation were not significantly different among hydroxyapatite, $\beta$-tricalcium phosphate and titanium. However, the activity of alkaline phosphatase, the concentration of osteocalcin and the formation of mineralized nodules revealed that the initial mineralization of osteoblast-like cells was better on Ca-P ceramics than on titanium, although no significant differences were found between $\beta$-tricalcium phosphate and hydroxyapatite. In conclusion, this study demonstrates that differences in the crystal system are not a predominant factor in the initial mineralization process of osteoblast-like cells, suggesting that the solubility of Ca-P ceramics may play an important role in the clinical implant treatment.
\end{abstract}

In clinical practice, it is recognized that osseointegration plays an important role in the success of dental implants. Although titanium (Ti) has a greater ability than other metals to facilitate osseointegration (1), the presence of amorphous structures between $\mathrm{Ti}$ and bone tissues introduces the risk of large gap formations and a loss of osseointegration under unfavorable conditions such as infection and overloading of the implants. In contrast, there have been a mumber of reports showing that the rate of osteogenesis in $\mathrm{Ti}$ and $\mathrm{Ti}$ alloy implants is lower than in calcium phosphate (Ca-P) implant materials $(24,30,31)$.

$\mathrm{Ca}-\mathrm{P}$ is well known to support osteogenesis in the

Correspondence to: Dr. K. Matsuzaka

Oral Health Science Center, Department of Clinical Pathophysiology, Tokyo Dental College, 1-2-2, Masago, Mihama-ku, Chiba, 261-8502 Japan

Tel: +81-43-270-3581, Fax: +81-43-270-3583

e-mail: matsuzak@tdc.ac.jp early stage of implantation with direct binding to bone tissue in vivo (2), and it has been used as a coating material on $\mathrm{Ti}$ oral implants for many years with favorable results $(6,11,12,20,24-26,29-31)$. Furthermore, extracellular matrix (ECM) formation was greater on Ca-P coated $\mathrm{Ti}$ implants than on $\mathrm{Ti}$ alone in vitro (10). Several mechanisms involved in osteogenesis on Ca-P ceramics have been considered as principal factors. For example, calcium ions might dissolve from the $\mathrm{Ca}-\mathrm{P}$ surface, resutting in the deposition of a mineralized layer. This would stimulate the bone cells to continue ECM (bonding zone) synthesis and calcification. It is also known that $\mathrm{Ca}-\mathrm{P}$ ceramics adsorb many osteo-conductive and/or osteo-inductive proteins, which play important roles in the mineralization of bone tissues. Thus, Ca-P coated implants may have a higher capacity to support the proliferation and differentiation of osteoblast progenitor cells around the implant surfaces (18). 
Hydroxyapatite and beta tricalcium phosphate $(\beta$ TCP) are major materials with clinical application among the various types of $\mathrm{Ca}-\mathrm{P}$ ceramics because of their comparatively low dissolution rate as well as their excellent biocompatibility (27). Many studies have dealt with the effects of Ca-P ceramic crystallinity on cell responses $(2,22,28)$, and compared hydroxyapatite and $\beta$-TCP with different solubilities on osteoblast response (27). Those studies showed that the amounts of newly formed bone around hydroxyapatite were more extensive than those around $\beta$-TCP. Further, the deposition of calcium and phosphate on the substrate surface was greater on $\beta$-TCP than on hydroxyapatite (5). Several additional factors, such as the $\mathrm{Ca} / \mathrm{P}$ ratio, the porosity, the grain size, and the crystallinity of the material, have been shown to influence the rate of degradation of calcium phosphate coating and cell behavior $(4,15)$. However, the major factors involved in the mineralization process of $\mathrm{Ca}-\mathrm{P}$ ceramics are not fully understood, including the roles of the crystal system, the $\mathrm{Ca} / \mathrm{P}$ ratio, the solubility and the surface morphology of the material. The crystal systems of $\beta$-TCP and hydroxyapatite are triagonal and hexagonal, and their $\mathrm{Ca} / \mathrm{P}$ ratios are 1.50 and 1.67 , respectively. In general, although $\beta$-TCP has a higher solubility than hydroxyapatite, it is known that the solubility can be controlled by adjusting the sintering temperature (32).

Therefore, this study was performed to evaluate the initial mineralization behavior of osteoblast-like cells on Ca-P ceramics, which have different crystal systems (and $\mathrm{Ca} / \mathrm{P}$ ratios) but similar solubilities and surface morphologies.

\section{MATERIALS AND METHODS}

Preparation of experimental discs. Two different kinds of Ca-P ceramics, $\beta$-TCP and hydroxyapatite, were prepared as test discs, $13 \mathrm{~mm}$ in diameter and $1 \mathrm{~mm}$ in thickness. Sintering temperatures of $\beta$-TCP and hydroxyapatite at 1100 and $1250^{\circ} \mathrm{C}$, respectively, yield similar solubilities between $\beta$-TCP and hydroxyapatite, according to Yoshinari et al. $(30,32)$. Commercially pure $\mathrm{Ti}$ (cp-Ti, Type 2) discs were also prepared in the same manner as a control. The surfaces of these discs were ground using 1200 grit $\mathrm{SiC}$ paper, and then were polished using $0.3-\mu \mathrm{m}$ alumina. The surface morphologies of these materials were mirror surfaces with Ra of less than $0.2 \mu \mathrm{m}$ and rare porosities. All discs were cleaned ultrasonically and then sterilized in an autoclave for $10 \mathrm{~min}$ at $135^{\circ} \mathrm{C}$.
Characterization of $\mathrm{Ca}-\mathrm{P}$ discs. The crystal systems and solubilities of two types of $\mathrm{Ca}-\mathrm{P}$ ceramics were evaluated. The crystal system was analyzed using an X-ray diffractometer (Rint-2000; Rigaku, Tokyo, Japan). To determine the solubility of each type of $\mathrm{Ca}-\mathrm{P}$ disc, it was immersed in $1.0 \mathrm{ml} 0.9 \% \mathrm{NaCl}$ at $37^{\circ} \mathrm{C}$ for 7 days, then the concentrations of $\mathrm{Ca}^{2+}$ and $\mathrm{PO}_{4}{ }^{3-}$ were quantified using an ion chromatograph (LC-VP; Shimadzu Co. Ltd, Kyoto, Japan).

Cell culture. For biological evaluation of the test discs, a rat bone marrow (RBM) cell culture technique was used according to the method of Maniatopoulos et al. (16). Briefly, RBM cells were obtained from femora of male Wistar rats, weighing 100-200 $\mathrm{g}$. The epiphyses were cut off, and RBM cells in the diaphyses were flushed out, using alpha-MEM (Gibco Life Technologies B.V., Breda, The Netherlands) supplemented with $10 \%$ fetal calf serum (FCS, heat treated at $56^{\circ} \mathrm{C}$ for $35 \mathrm{~min}$, Gibco), 50 $\mathrm{mg} / \mathrm{ml}$ freshly prepared ascorbic acid (Sigma Chemical Co., St. Louis, MO, USA), $10 \mathrm{mM}$ Na betaglycerophosphate (Sigma), $10^{-8} \mathrm{M}$ dexamethasone (Sigma) and antibiotic (gentamicin). Cells were suspended and cultured in three $80 \mathrm{~cm}^{2}$ tissue culture flasks (Nunc Products by Gibco). Finally, cultures were incubated in a humidified atmosphere of $95 \%$ air and $5 \% \mathrm{CO}_{2}$ at $37^{\circ} \mathrm{C}$. After 8 days of primary culture, cells were detached using trypsin/EDTA $(0.25 \% \mathrm{w} / \mathrm{v}$ trypsin $/ 0.02 \%$ EDTA at $\mathrm{pH} 7.2)$. Subsequently, cells were resuspended in the supplemented culture medium as described above, and used for the experiments.

Each disc was placed into a well of a 24 well culture plate (Falcon Becton Dickinson Co. Ltd., NJ, USA), and cells were seeded at densities of $1.0 \times 10^{4} / \mathrm{cm}^{2}$ on each disc.

Cell attachment and cell proliferation assay. The cell attachment assay was carried out as described by Keller et al. (14). Briefly, at the end of 2, 4 or 6 $\mathrm{h}$ incubation periods, cell suspensions were carefully removed by a pipette and the disc surfaces were rinsed twice with phosphate buffered saline (PBS) to remove non-adherent cells on the surface. Adherent cells were then counted using a Coulter counter (Coulter, Z-1) after detaching the cells with $0.05 \%$ trypsin solution containing $0.02 \%$ EDTA. For the proliferation assay, cells were counted at 1,3 and 5 days of incubation as noted above for the cell attachment assay.

Alkaline phosphatase assay. After removal of the 
culture medium, the cell layers were rinsed in PBS. De-mineralized $\mathrm{H}_{2} \mathrm{O}$ (milli Q) was then added to each specimen and put on ice. Finally, the cells were harvested with a rubber scraper and the cell suspensions were transferred to $10 \mathrm{ml}$ tubes. The cells were sonicated for $10 \mathrm{~min}$, and centrifuged at $2000 \mathrm{rpm}$ for $10 \mathrm{~min}$. Subsequently, a $10 \mu \mathrm{l}$ aliquot of each cell lysate plate was incubated for $1 \mathrm{~h}$ at $37^{\circ} \mathrm{C}$ in a working reagent consisting of $0.5 \mathrm{M} 2 \mathrm{~S}$ amino-2-methyl-1-propanol (Sigma), $5 \mathrm{mM}$ p-nitrophenol phosphate (Sigma), and $5 \mathrm{mM}$ magnesium chloride $(1: 1: 1)$. The reaction was stopped by the addition of $100 \mu \mathrm{l} 0.3 \mathrm{M}$ sodium hydroxide, and the final absorbance was read at $405 \mathrm{~nm}$ using a microplate reader (Biorad 450; Bio Rad, CA, USA).

To determine the specific activity of ALP, protein contents in the same lysates were determined using the Pierce BCA protein assay (Pierce, IL, USA). A $150 \mu 1$ aliquot of each cell lysate was added to 150 $\mu 1 \mathrm{BCA}$ working reagent in a 96 well culture plate and incubated for $2 \mathrm{~h}$ at $37^{\circ} \mathrm{C}$. Absorbances were then measured at $562 \mathrm{~nm}$ using the microplate reader.

The ALP specific activity was determined using the following formula:

ALP specific activity $(\mu \mathrm{mol} / \mu \mathrm{g} / \mathrm{min})=$

ALP specific concentration $(\mu \mathrm{mol} / \mathrm{ml})$ Protein concentration $(\mu \mathrm{g} / \mathrm{ml})$

\section{$\times \frac{1}{\text { ALP incubation time (min) }}$}

Two independent experiments were carried out for all assays, and two specimens of each sample type were used in each experiment.

Concentration of osteocalcin. Osteocalcin concentration was analyzed at 5,9 and 13 days of culture by biochemical assay using the RAT OSTEOCALCIN EIA KIT (Biomedical Technologies Inc., MA, USA). One $\mathrm{ml}$ of culture medium containing $10 \%$ fetal bovine serum (FBS) was added to each disc. After $48 \mathrm{~h}$, the culture medium was removed and kept at $-80^{\circ} \mathrm{C}$ until measurements were performed. $\mathrm{Ab}$ sorbance was measured at $450 \mathrm{~nm}$ using a microplate reader (Model 3550 MICROPLATE READER; Bio Rad, CA, USA)

Scaming electron microscopy (SEM). To prepare specimens for SEM, the medium was removed and discs were rinsed twice with PBS. Cells and matrix were then fixed in $0.25 \%$ glutaraldehyde with $0.1 \mathrm{M}$ sodium cacodylate buffer $\left(\mathrm{pH} 7.2,37^{\circ} \mathrm{C}\right)$, dehydrated in a graded series of ethanol and dried with by tetramethylsilane. Images were obtained using a scanning electron microscope (JSM-6340F; JEOL, Tokyo, Japan) at 9 and 13 days of incubation. Mineralized nodules were analyzed by means of Scion Image software (Scion Corporation, MD, USA).

Electron probe microanalyzer (EPMA) analysis. To confirm the formation of mineralized nodules, the distribution of calcium and phosphate were analyzed by EPMA (X-3010; HITACHI, Tokyo, Japan). On specimens after 13 days of incubation, in order to avoid the $\mathrm{Ca}$ and $\mathrm{P}$ originating from the $\mathrm{Ca}-\mathrm{P}$ ceramic substrates, an adhesive carbon tape was affixed to the surface of each specimen, and then this tape was detached. Multi-layer of cells and matrix on the tapes were carbon-coated, and then EPMA analysis was performed.

Statistical analysis. Data obtained were analyzed via one-way ANOVA, then compared by the Fisher's PLSD (protected least significant difference) test at $\mathrm{p}=0.05$.

\section{RESULTS}

\section{Characteristics of $\mathrm{Ca}-\mathrm{P}$ discs}

The X-ray diffraction patterns of Ca-P are shown in Fig. 1. According to the JCPDS (Joint Committee on Powder Diffraction Standards) database, $\beta$-TCP and hydroxyapatite crystal systems were recognized on $\beta$-TCP and hydroxyapatite substrates, respectively. Cumulative amounts of $\mathrm{Ca}^{2+}$ and $\mathrm{PO}_{4}^{3-}$ released in $0.9 \% \mathrm{NaCl}$ over 7 days is shown in Fig. 2. There were no significant differences in either the $\mathrm{Ca}^{2+}$ or the $\mathrm{PO}_{4}^{3}$ concentration of $\beta-\mathrm{TCP}$ and hydroxyapatite.

\section{Cell attachment and cell proliferation assay}

The results of cell attachment and cell proliferation assays are shown in Fig. 3 and Fig. 4, respectively. The number of adhesive cells on each disc increased up to $6 \mathrm{~h}$, but no significant differences among the 3 types of discs were found from 2 to $6 \mathrm{~h}$ after cell seeding (Fig. 3). Furthermore, although the number of cells on each disc increased significantly from 1 to 7 days of incubation, there were no significant differences among the three types of discs (Fig. 4).

\section{ALP activity of RBM cells}

Fig. 5 shows the results of ALP activity after 5, 9 and 13 days of incubation. At 9 and 13 days, the 


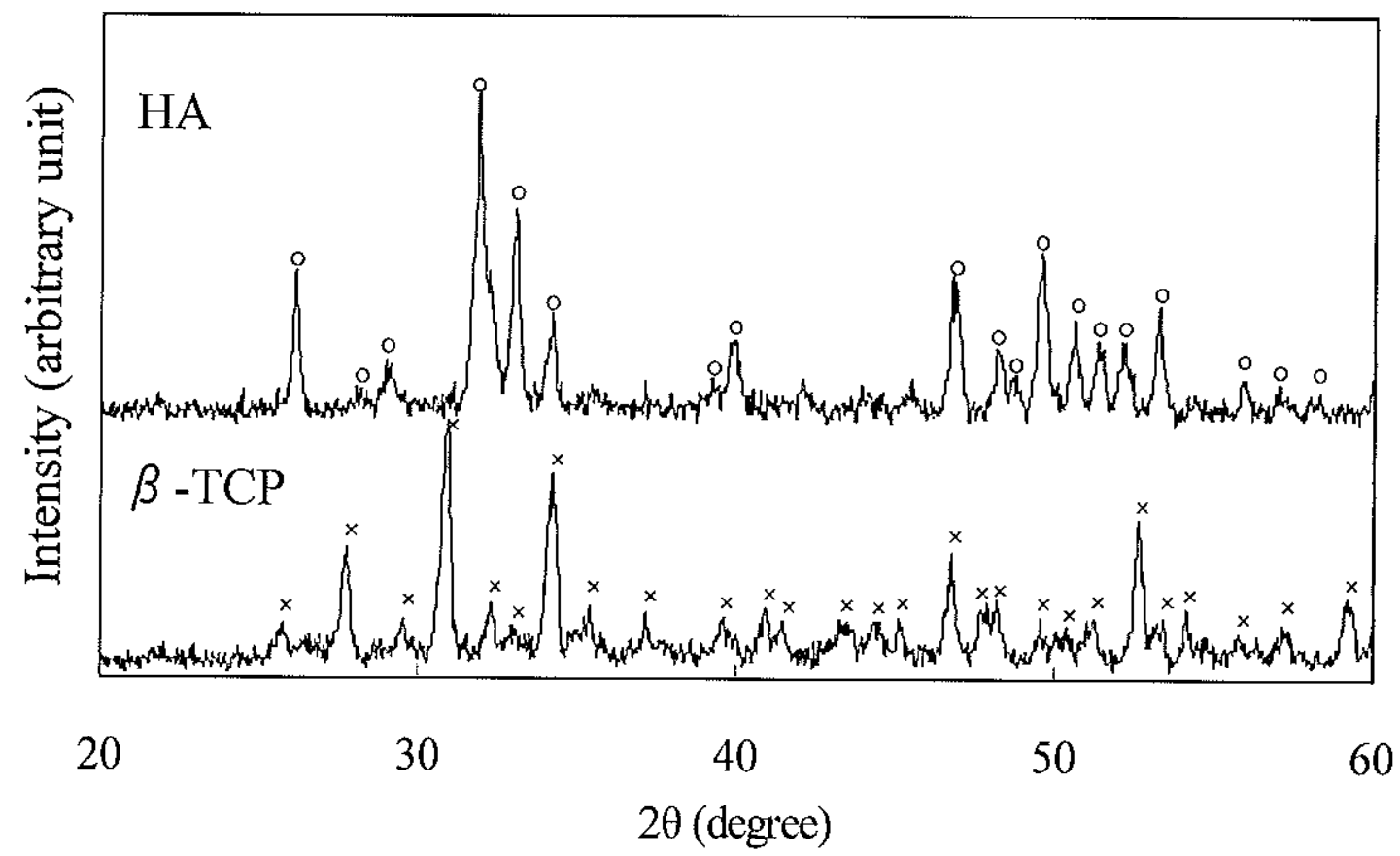

Fig. 1 -ray diffraction patterns with Ca-P ceramics (O: hydroxyapatite, $X: \beta$-TCP recognized by JCPDS cards). The substrates were recognized as $\beta$-TCP and hydroxyapatite, respectively.

ALP activity was higher in cells cultured on Ti than on either types of Ca-P ceramic substrates. Over time, the ALP activity on both types of Ca-P ceramics reached the maximum level on 9 days, whereas, ALP activity on Ti did not yet decrease on 13 days.

\section{Osteocalcin content}

The amount of osteocalcin discharged from RBM cells to the culture medium at 5,9 and 13 days of incubation is shown in Fig. 6. The osteocalcin concentrations on all types of discs at 9 days of incubation were significantly higher than those at 13 days of incubation. At 5 days of incubation, the osteocalcin concentrations of $\beta$-TCP and hydroxyapatite were higher than those of $\mathrm{Ti}$. There were no significant differences among the discs at 9 days of incubation.

\section{Scanning electron microscopy}

SEM images after 9 and after 13 days of incubation are shown in Fig. 7 and Fig. 8, respectively. After 9 days of incubation, a layer of mineralized globuli was detectable on all discs. On the $\beta$-TCP and hydroxyapatite discs, collagenous fibers with a number of mineralized nodules appeared, but on the $\mathrm{Ti}$ disc, cells produced only a small number of mineralized nodules. After 13 days of incubation, all the disks were completely covered by collagen with a large number of mineralized globuli (Fig. 8).
The sizes and the mineralized areas of the mineralized nodules are shown in Fig. 9 and Fig. 10, respectively. The size of the mineralized globuli on $\beta$-TCP and hydroxyapatite discs were significantly larger than those on $\mathrm{Ti}$ at 9 and 13 days of incubation, but there were no significant differences between $\beta$-TCP and hydroxyapatite. Further, the size of the mineralized globuli on all discs increased

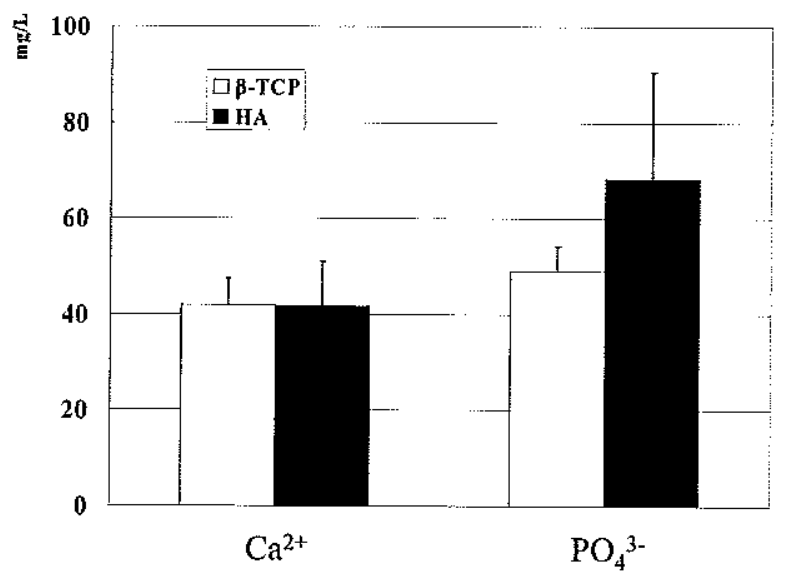

Fig. 2 Cumulative amounts of $\mathrm{Ca}^{2+}$ and $\mathrm{PO}_{4}{ }^{3-}$ released in $0.9 \% \mathrm{NaCl}$. There were no significant differences regarding $\mathrm{Ca}^{2+}$ and $\mathrm{PO}_{4}{ }^{3-}$ concentrations between $\beta$-TCP and hydroxyapatite released after immersion in $1 \mathrm{ml} 0.9 \% \mathrm{NaCl}$ at $37^{\circ} \mathrm{C}$ for 7 days. 


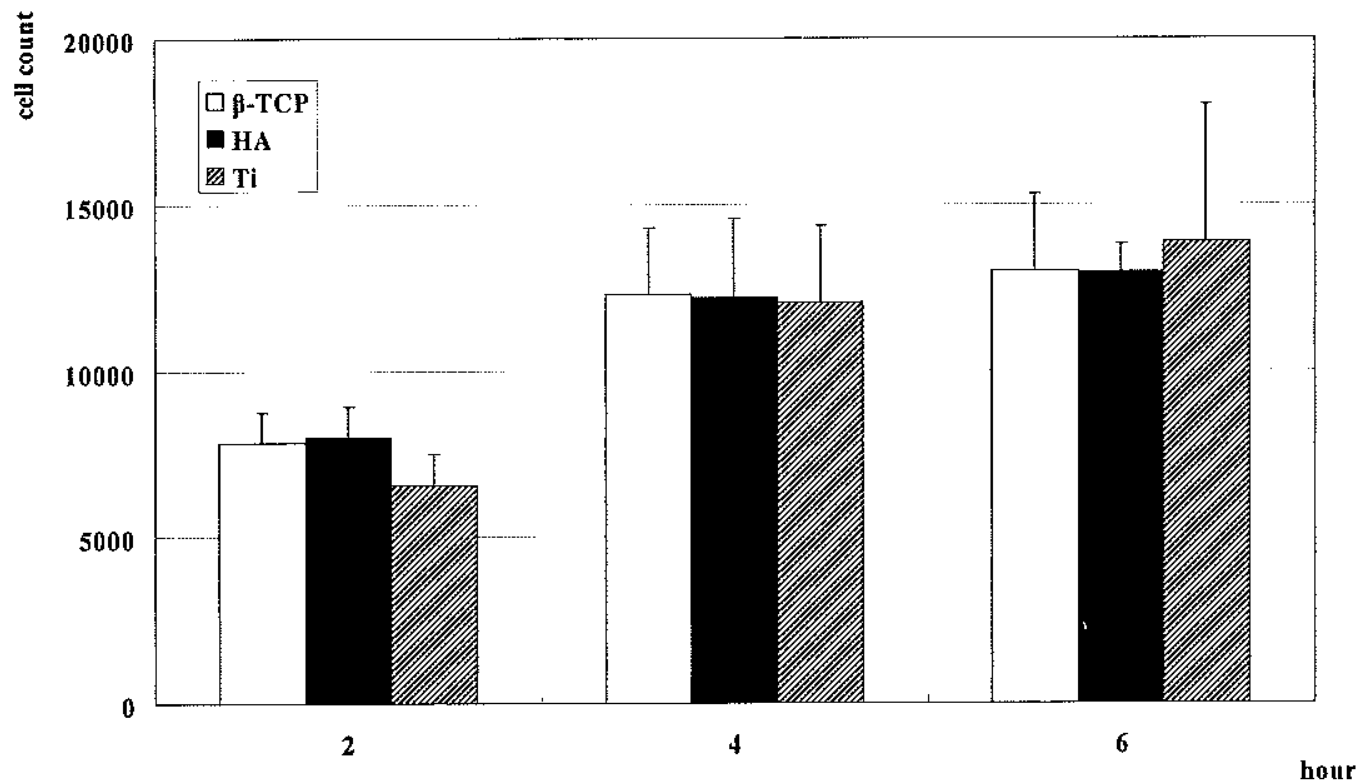

Fig. 3 Effect of Ca-P ceramics on cell attachment. Osteoblast-like cells were cultured on $\beta$-TCP, hydroxyapatite and Ti substrates. Cell attachment on each substrate was evaluated by recording the number of cells attached after 2,4 and $6 \mathrm{~h}$ of culture. No remarkable differences in cell attachment were noted between the substrates tested.

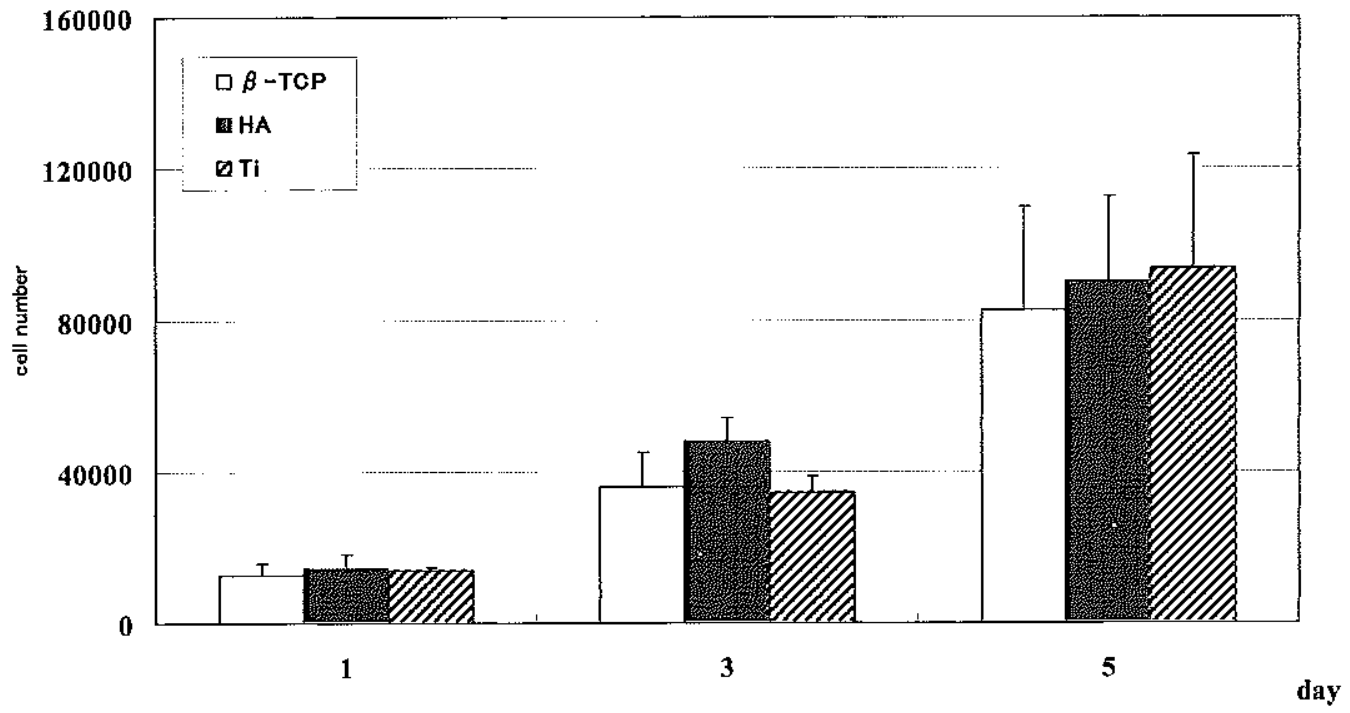

Fig. 4 Effect of Ca-P ceramics on cell proliferation. Osteoblast-like cells were cultured on $\beta$-TCP, hydroxyapatite and Ti substrates. Cell proliferation on each substrate was evaluated by recording the number of cells attached after 1,3 and 5 days of culture. No remarkable differences in cell proliferation were noted between the substrates tested.

from 9 to 13 days of incubation. The mineralized areas on both Ca-P discs were more extensive than on Ti discs at 9 and 13 days of incubation, and the areas increased from 9 days to 13 days of incubation.

\section{EPMA analysis}

Fig. 11 shows the EPMA analyses of the layer de- tached from hydroxyapatite at 13 days of cell culture. The presence of $\mathrm{Ca}$ and $\mathrm{P}$ was recognized in the same areas where mineralized nodules existed. The results obtained from the $\beta$-TCP and the Ti substrates were similar. 


\section{DISCUSSION}

In the present study, we focused on the initial mineralization behavior of osteoblast-like cells on $\beta$-TCP and hydroxyapatite, which are the major Ca-P ceramics used as dental implant materials (27). $\beta$-TCP and hydroxyapatite have different crystal systems and $\mathrm{Ca} / \mathrm{P}$ ratios, and $\beta$-TCP generally has a higher

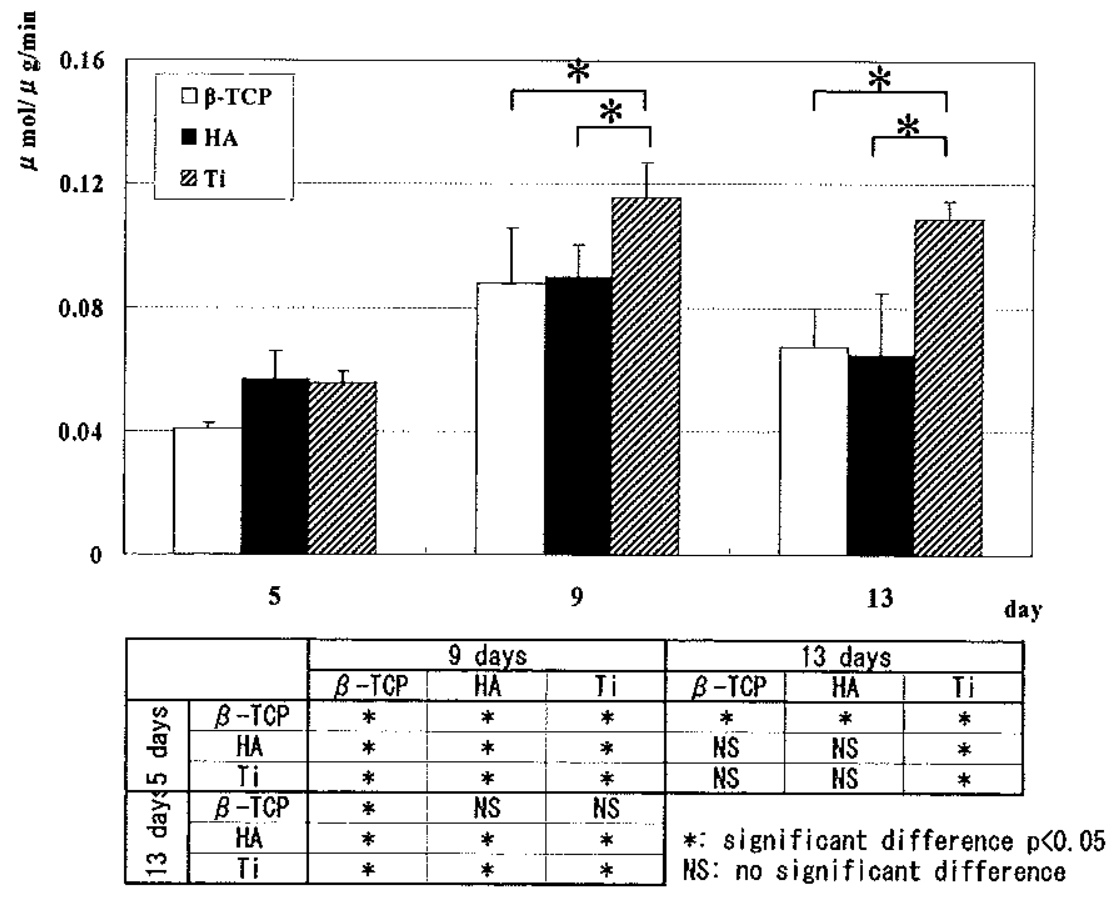

Fig. 5 ALP activity after 5,9 and 13 days of incubation.

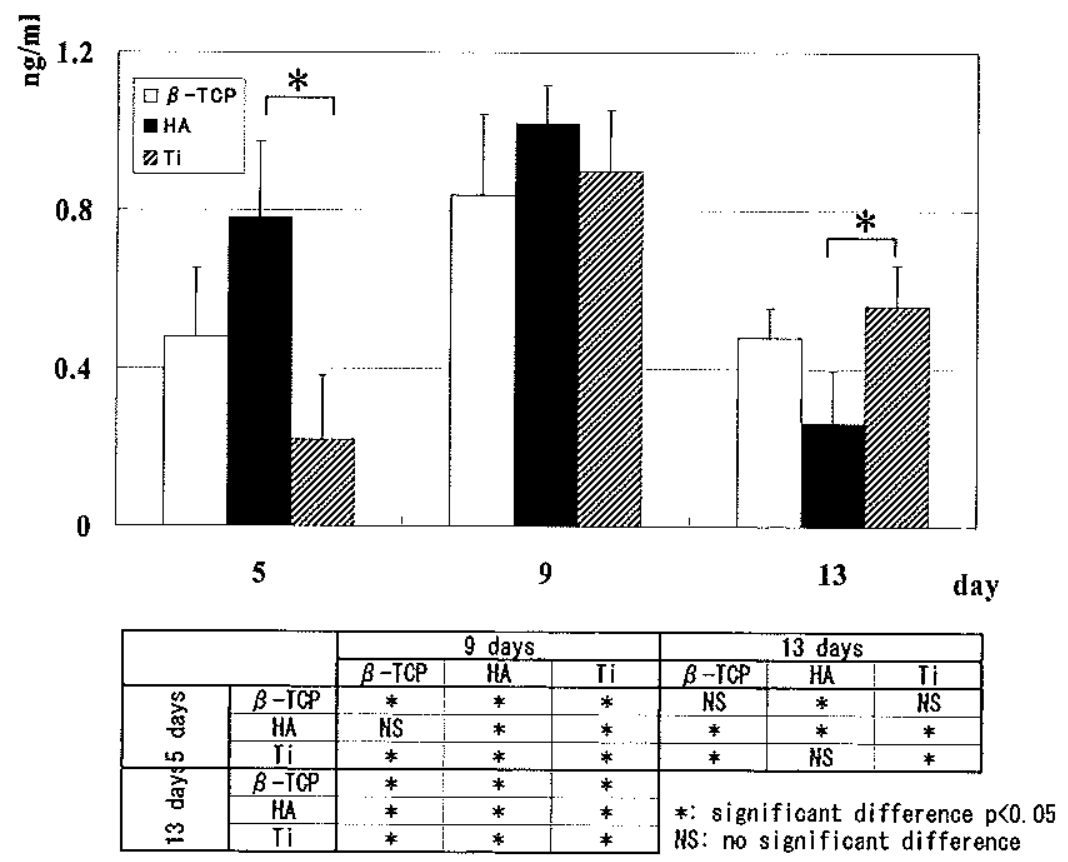

Fig. 6 Osteocalcin concentration in the culture medium after 5,9 and 13 days of incubation. 

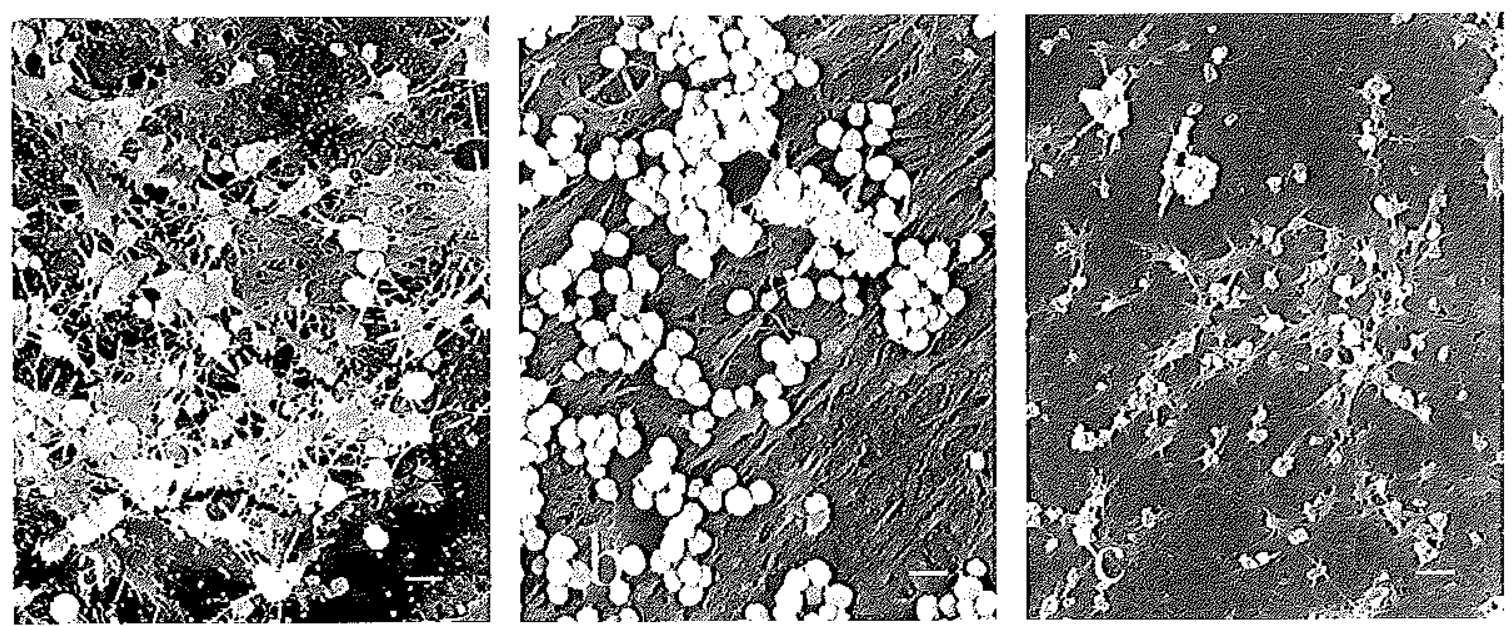

Fig. 7 SEM micrograph on the surface of the cell layer after 9 days (a: $\beta-T C P, b$ : hydroxyapatite, $\mathrm{c:} \mathrm{Ti,} \mathrm{bar}=1 \mu \mathrm{m})$. Ca-P ceramic substrates showed a greater number of collagenous fibers as well as mineralized nodules than $\mathrm{Ti}$.
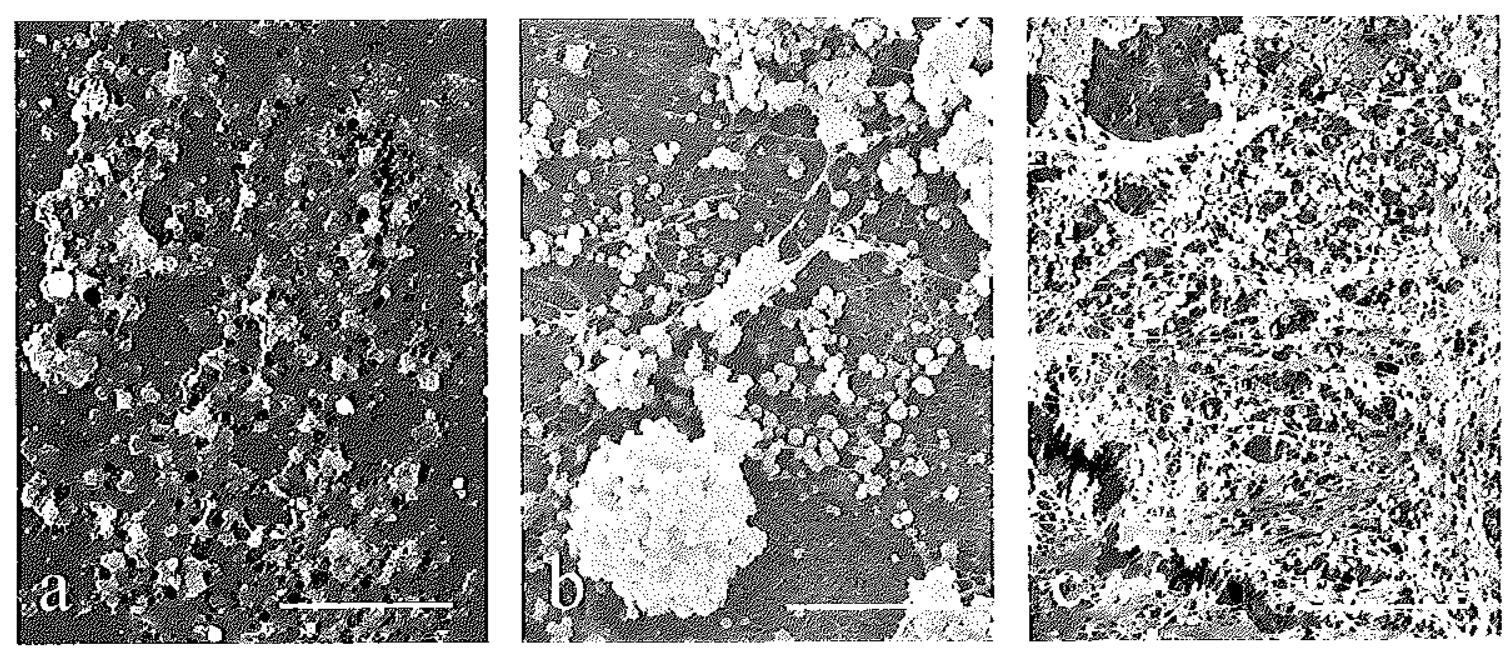

Fig. 8 SEM micrograph on the surface of the cell layer after 13 days (a: $\beta$-TCP, b: hydroxyapatite, $\mathrm{C}:$ Ti, bar $=10 \mu \mathrm{m}$ ). Mineralized nodules were present in all the substrates tested. Moreover, areas of concentration of mineralized nodules were also recognized.

solubility than hydroxyapatite on commercially available products $(4,15)$. Although many reports have discussed about solubility and crystal structure of $\beta$-TCP and hydroxyapatite on the mineralization process, it is still not fully understood which factor is predominant in the mineralization process. This means not to be controlled by the solubility of $\beta$ TCP and hydroxyapatite. Moreover, it has been mentioned that the surface morphology may affect the response of osteoblast-like cells around the implant surface $(7,17,19)$. Therefore, in this study, we compared $\beta$-TCP and hydroxyapatite, which have different crystal systems, but similar solubilities and surface morphologies, on the mineralization process.
The solubility of $\beta$-TCP and hydroxyapatite was controlled by adjusting the sintering temperature.

Regarding the results of the initial cell attachment, there were no remarkable differences between the substrates tested. Hulshoff et al. (10) reported that no significant differences existed between the attachment percentages of RBM cells to Ca-P and Ti. It has been mentioned that the crystallinity of Ca-P substrates does not influence cell attachment, but that $\mathrm{Ca}^{2+}$ in the culture medium does affect it (3, 13). This study also suggests that the crystal system of Ca-P does not influence the initial cell attachment under the similar low solubilities of $\beta$-TCP and hydroxyapatite. 


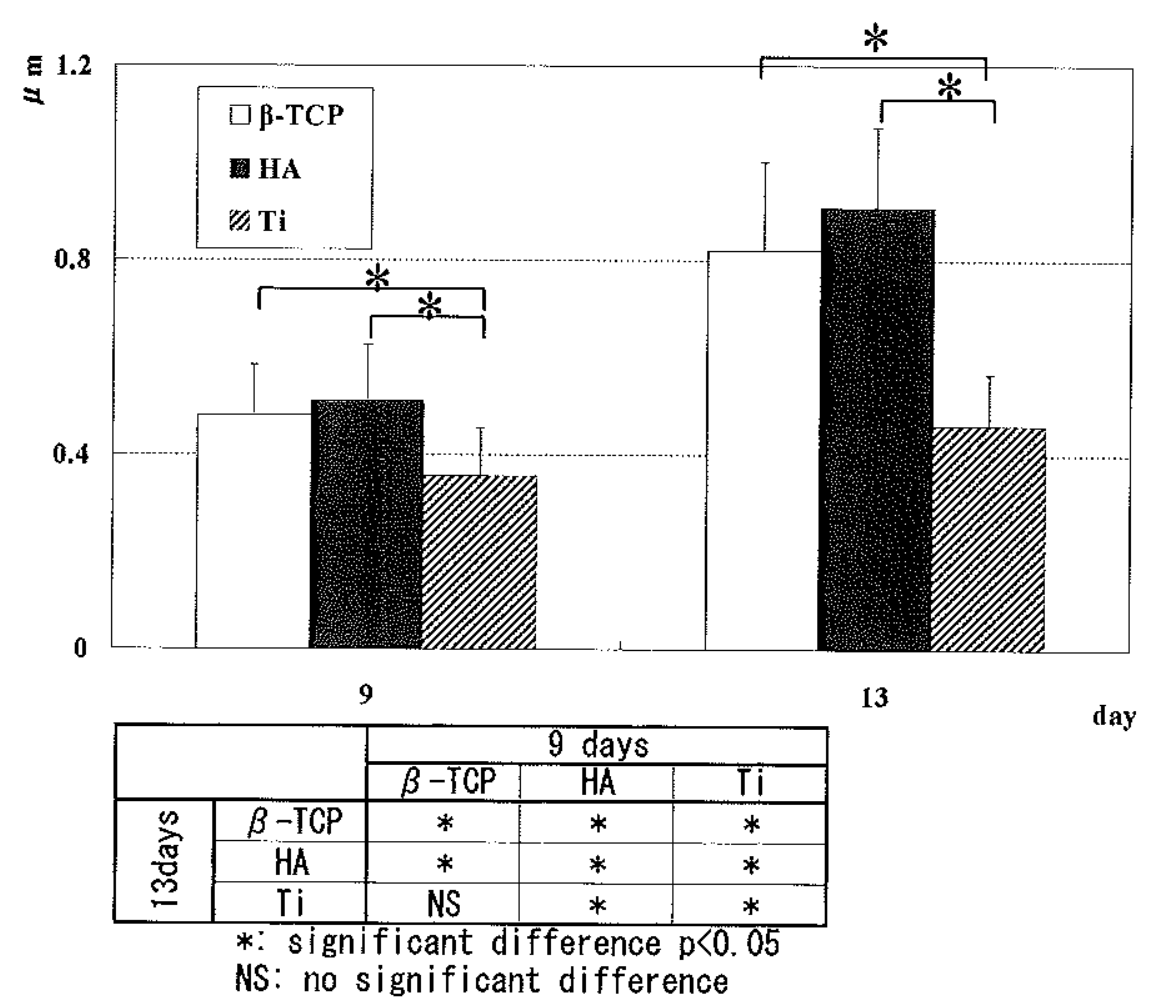

Fig. 9 Size of mineralization nodules on each substrate. Mineralization nodules were measured after 9 and 13 days of culture. The diameters of the mineralized nodules formed at 9 days and at 13 days of culture were significantly higher in the Ca-P ceramic substrates than in the Ti substrate $(p<0.05)$.
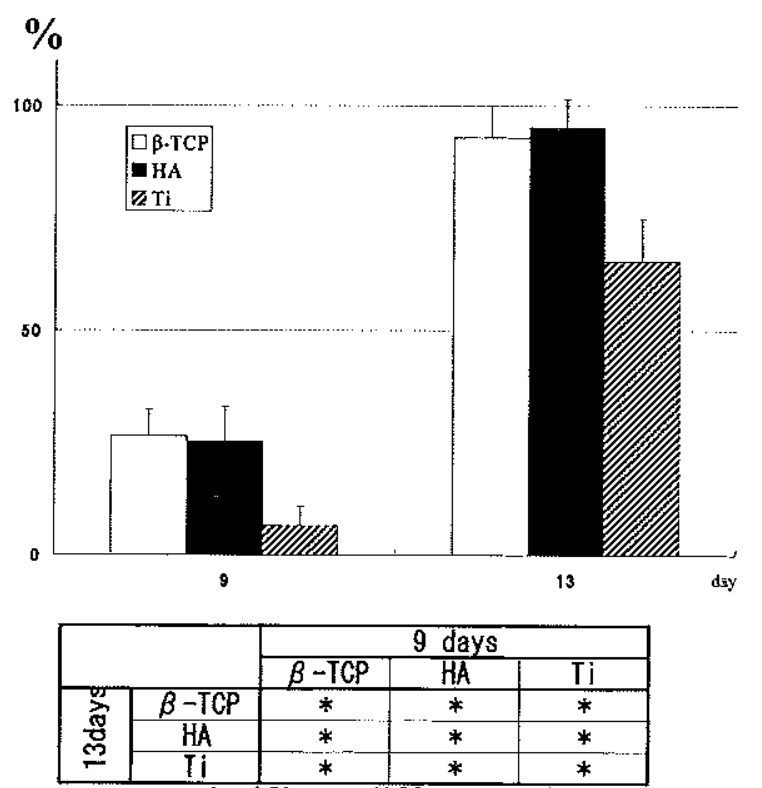

$*$ : significant difference $p<0.05$

Fig. 10 Percent area of mineralized nodules on each substrate. The area of the mineralized nodules on Ca-P ceramic substrates was higher than on the Ti substrate.
Sun et al. mentioned that $\mathrm{Ca}-\mathrm{P}$ had an inhibitory effect on the growth of osteoblasts in vitro (27). Hulshoff $e t$ al. reported that the proliferation rates of RBM cells on Ti were higher than on Ca-P (9). On the other hand, similar proliferation of RBM cells on Ca-P discs and on Ti dises was shown in this study. One possible explanation for these results was that the discs used in this study had similar mirror-like surfaces, and comparatively low dissolution rates of Ca-P ceramics compared to those used in previously reported investigations.

The ALP activities and osteocalcin concentrations on the two types Ca-P ceramics reached the maximum level more quickly than those of $\mathrm{Ti}$, but there were no significant differences between $\beta$-TCP and hydroxyapatite. The manifestation of osteoblast function is considered to follow a four-stage sequence of events; the secretion of collagen fibers, the expression of ALP, the discharge of osteocalcin, and the incorporation of osteocalcin into collagen. In the present study, it is recognized that ALP activity, an index of osteoblast expression at the initial stage, still remained on $\mathrm{Ti}$ at day 13 , ath the concentration of osteocalcin on Ca-P ceramics was higher than on 

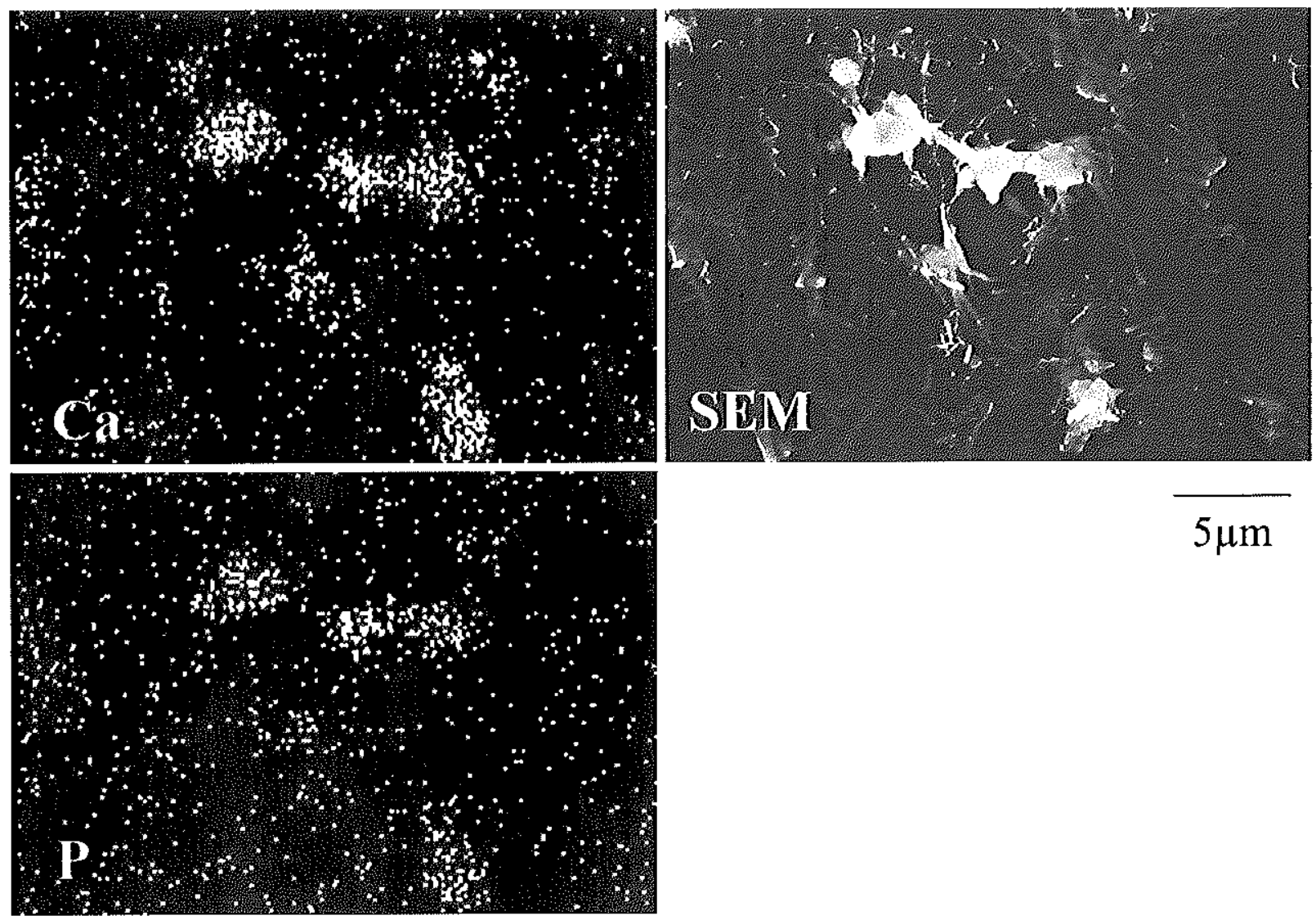

\section{$5 \mu \mathrm{m}$}

Fig. 11 EPMA characteristic images. $\mathrm{Ca}$ and $\mathrm{P}$ were observed in the area where nodules were present.

Ti at day 5. The low rate of decrease in ALP activity on Ti compared to Ca-P at day 13 may be due to the remaining osteoblasts in the initial stage of differentiation. These results suggest that $\mathrm{Ca}-\mathrm{P}$ ceramics may be a more hospitable substrate for the differentiation of osteoblasts than $\mathrm{Ti}$ (18).

SEM observations revealed that not only did Ca-P ceramic substrates show a large number of mineralized nodules earlier than the Ti substrate, but that these mineralized nodules were bigger in size than those observed on the Ti substrate. However, no significant differences were found between either of the Ca-P ceramics. Extracellular matrices were produced by osteoblasts, subsequently the formation of the mineralize nodules occurred. It has been reported that $\mathrm{Ca}$ and $\mathrm{P}$ co-localize in and around calcified nodules (8). This means that the size of mineralized nodules play an important role for bone formation.

Based on the results of our in vitro experiments, we consider that the initial mineralization of osteoblast-like cells is better on Ca-P ceramics than on $\mathrm{Ti}$, but no significant differences were found be- tween $\beta$-TCP and hydroxyapatite. $\beta$-TCP has been thought to be a precursor of bone mineralization, and to show better mineralization ability than hydroxyapatite (21). In vivo, it was reported that hydroxyapatite might not initially precipitate, but $\mathrm{Ca}-\mathrm{P}$ compounds with high solubility were separated as precursors and were changed by a phase transition to hydroxyapatite. TCP has been considered as a precursor that plays a major role in mineralization (23). However, the results of our study were different from previous reports. The reason for these differences may be attributed to the fact that the $\beta$-TCP used in those previous studies had a higher solubility than hydroxyapatite. Those previous studies did not compare Ca-P ceramics with similar solubility as we did in this study. Accordingly, it had not been fully clarified which factor was predominant in the mineralization process of osteoblasts.

In conclusion, this study indicates that differences in the crystal system are not a predominant factor in the initial mineralization process of osteoblasts, which suggests that the solubility of Ca-P ceramics may play an important role for clinical implant 
treatment.

\section{Acknowledgment}

This study was partially supported by Oral Health Science Center grant (HRC 992C01) to the Tokyo Dental College.

\section{REFERENCES}

1. Albrektsson T. and Jacobsson M. (1987) Bone-metal interface in osseointegration. J. Prosthet. Dent. 57, 597-607.

2. Chang Y., Stanford C. M, Wefel J. S. and Keller J. C. (1999) Osteoblastic cell attachment to hydroxyapatite-coated implant surfaces in vitro. Int. J. Oral Maxillofac. Implants 14, 239-247.

3. Chou L., Marek B. and Wagner W. R. (1999) Effects of hydroxyapatite coating crystallinity on biosolubility, cell attachment efficiency and proliferation in vitro. Biomaterials 20, $977-985$.

4. De Groot K. (1998) Effect of porosity and physicochemical properties on the stability, resorption, and strength of calcium phosphate ceramics. Ann. N. Y. Acad. Sci. 523, 227-233.

5. Fujita R., Wakasa R., Yokoyama A., Komatsubara H., Takeishi A., Kawasaki T. and Kohgo T. (2000) Onlay graft of hydroxyapatite and $\beta$-tricalcium phosphate blocks on the bone. Hokkaido J. Dent. Sci. 21, 118-129.

6. Gottlander M., Albrektsson T. and Carlsson L. V. (1992) A histomorphometric study of unthreaded hydroxyapatitecoated and titanium-coated implants in rabbit bone. Int. $J$. Oral Maxillofac. Implants 7, 485-490.

7. Hatano K. (1999) Effect of surface roughness of culture substrate on proliferation and differentation of rat calvarial cells. J. Kyushu Dent. Soc, 53, 139-148.

8. Hoshi K., Amizuka N., Kurokawa T. and Ozawa H. (1997) Ultrastructure and immunolocation of transforming growth factor-beta in chondrification of murine ligamentous fibroblasts and endochondral calcification induced by recombinant human bone morphogenetic protein-2. Acta Histochem. Cytochem. 30, 371-379.

9. Hulshoff J. E., van Dijk K., de Ruijter J. E., Rietveld F. J., Ginsel L. A. and Jansen J. A. (1998) Interfacial phenomena: an in vitro study of the effect of calcium phosphate (Ca-P) ceramic on bone formation. J. Biomed. Mater. Res. 40, 464-474.

10. Hulshoff J. E., van Dijk K., van der Waerden J. P., Wolke J. G., Ginsel L. A. and Jansen J. A. (1995) Biological evaluation of the effect of magnetron sputtered $\mathrm{Ca} / \mathrm{P}$ coatings on osteoblast-like cells in vitro. J. Biomed. Mater. Res. 29, 967-975.

I1. Jansen J. A., van der Waerden J. P., van der Lubbe H. B. and de Groot K. (1990) Tissue response to percutaneous implants in rabbits. J. Biomed. Mater. Res. 24, 295-307.

12. Jansen J. A., Wolke J. G. C., van der Waerden J. P. C. M. and de Groot K. (1993) Application of magnetron sputtering for producing ceramic coating on implant materials. Clin. Oral Impl. Res. 4, 28-34.

13. Keller J. C., Collins J. G., Niederauer G. G. and McGee T. D. (1997) In vitro attachment of osteoblast-like cells to osteoceramic materials. Dent. Mater: 13, 62-68.

14. Keller J. C., Dongherty W. J., Grotendorst G. R and Winghtman J. P. (1989) In vitro cell attachment to characterization
cpTi surfaces. $J$. Adhesion 28, 115-133.

15. Le Geros R. Z. (1974) Variations in the crystalline components of human dental calculus. I. Crystallographic and spectroscopic methods of analysis. J. Dent. Res. 53, 45-50.

16. Maniatopoulous C., Sodek J. and Melcher A. H. (1988) Bone formation in vitro by stromal cells obtained from bone marrow of young adult rats. Cell Tissue Res. 254, 317-330.

17. Martin J. Y., Schwartz Z., Hummert T. W., Schraub D. M., Simpson J., Lankford J., Dean D. D., Cochran D. L. and Boyan B. D. (1995) Effect of titanitum surface roughness on proliferation, differentiation, and protein synthesis of human osteoblast-like cells (MG63). J. Biomed. Mater: Res. 29, 389-401.

18. Massas R., Pitaru S. and Weinreb M. M. (1993) The effects of titanium and hydroxyapatite on osteoblastic expression and proliferation in rat parietal bone culture. J. Dent. Res. 72, $1005-1008$.

19. Matsuzaka K., Walboomers X. F., Rujiter J. E. and Jansen J. A. (1999) The effect of poly-L-lactic acid with parallel surface micro groove on osteoblast-like cells in vitro. Biomaterials 20, 1293-1301.

20. Maxian S. H., Zawadsky J. P. and Dunn M. G. (1993) In vitro evaluation of amorphous calcium phosphate and poorly crystallized hydroxyapatite coatings on titanium implants. $J$. Biomed. Mater. Res. 27, 111-117.

21. Miake Y., Yanagisawa T., Yajima Y., Noma H., Yasui Y. and Nonami T. (1995) High-resolution and analytical electron microscopic studies of new crystals induced by a bioactive ceramic (Diopside). J. Dent. Res. 74, 1756-1763.

22. Morgan J., Holtman K. R., Keller J. C. and Stanford C. M. (1996) $I n$ vitro mineralization and implant calcium phosphatehydroxyapatite crystallinity. Implant Dent. 5, 264-271.

23. Okazaki M. (1992) Crystal structures. In: Chemistry of Apatites, pp. 1-26, Tokai University Press, Tokyo.

24. Okumori N., Yoshinari M. and Oda Y. (2000) Surface analysis of failed hydroxyapatite-coated implant. Shikwa Gakuho 100, 737-753.

25. Ozawa S. and Kasugai S. (1996) Evaluation of implant materials (hydroxyapatite, glass-ceramics, titanium) in rat bone marrow stromal cell culture. Biomaterials 17, 23-29.

26. Puleo D. A., Holleran L. A., Doremus R. D. and Bizios R. (1991) Osteoblast responses to orthopedic implant materials in vitro, J. Biomed. Mater. Res. 25, 711-723.

27. Sun J. S., Tsuang Y. H., Liao C. J., Liu H. C., Hang Y. S. and Lin F. H. (1996) The effects of calcium phosphate particles on the growth of osteoblast. J. Biomed. Mater. Res. 37, 324-334.

28. Villarreal D. R., Sogal A. and Ong J. L. (1998) Protein adsorption and osteoblast responses to different calcium phosphate surfaces. J. Oral Implantlogy 24, 67-73.

29. Weinlaender M., Kenney E. B., Lekovic V., Beumer J. 3rd, Moy P. K. and Lewis S. (1992) Histomorphometry of bone apposition around three types of endosseous dental implants. Int. J. Oral Maxillofac. Implants 7, 491-496.

30. Yoshinari M., Watanabe Y., Ohtsuka Y. and Derand T. (1997) Solubility control of thin calcium-phosphate coating with rapid heating. J. Dent. Res. 76, 1486-1495.

31. Yoshinari M., Ozeki K. and Sumii T. (1991) Properties of hydroxyapatite-coated $\mathrm{Ti}-6 \mathrm{Al}-4 \mathrm{~V}$ alloy produced by the ionplating method. Bull. Tokyo Dent. Coll. 32, 147-156.

32. Yoshinari M., Ohtsuka Y. and Derand T. (1994) Thin hydroxyapatite coating produced by the ion beam dynamic mixing method. Biomaterials 15, 529-535. 